\title{
Oviposition and Development in Gregopimpla kuwanae Viereck (Hymenoptera: Ichneumonidae), a Gregarious Ectoparasitoid Wasp Attacking the Rice Skipper Parnara guttata
}

\author{
Takatoshi Ueno \\ Institute of Biological Control, Faculty of Agriculture, Kyushu University, Fukuoka 812-8581, Japan \\ Correspondence should be addressed to Takatoshi Ueno; ueno@grt.kyushu-u.ac.jp
}

Received 16 November 2015; Revised 13 January 2016; Accepted 13 January 2016

Academic Editor: Francisco de Sousa Ramalho

Copyright ( $\odot 2016$ Takatoshi Ueno. This is an open access article distributed under the Creative Commons Attribution License, which permits unrestricted use, distribution, and reproduction in any medium, provided the original work is properly cited.

Gregopimpla kuwanae is a gregarious ectoparasitoid wasp attacking mature larvae and prepupae of the rice skipper Parnara guttata (Lepidoptera: Hesperiidae), a major herbivorous pest in rice paddies. Here, the biology of G. kuwanae was investigated using Galleria mellonella as a laboratory host. Adult females accepted G. mellonella cocoons for oviposition, and larvae of G. kuwanae developed successfully to adulthood on this host. Females laid, on average, 3.5 eggs per host. Time required for oviposition was relatively long ( mean $=14.2 \mathrm{~min}$ ). Survival of parasitoid offspring decreased with the increasing number of eggs on each host. Females used $18.9 \%$ of hosts for host feeding, killing the hosts with no exception. Oviposition did not occur on hosts used for feeding purpose, indicating that the parasitoid was a nonconcurrent, destructive host feeder. Newly emerging adult females carried no eggs in the ovary; females started oogenesis only after they had destructively fed on hosts. This parasitoid thus was extremely synovigenic (ovigeny index $=$ 0). Gregopimpla kuwanae laid typically yolk-rich, anhydropic eggs. Females carried on average 15 mature eggs with 20 immature eggs, and larger females had a greater number of eggs in the ovary. Life history characteristics of G. kuwanae were discussed.

\section{Introduction}

Growing attention has been paid to the role of agricultural fields to support biodiversity and the role of agrobiodiversity including beneficial pollinators and natural enemies as elements on sustainable production in agriculture [1-5]. Rice paddies support one of the largest insect communities among agricultural systems in Asia [6,7]. Insect community in rice paddies includes a variety of natural enemies that help control of rice pests $[8,9]$. Environmentally benign rice production should therefore apply farming practices that could be least influential to the natural enemies, including parasitoids and predators, to enhance biological pest control. Such practices may also help conserve agrobiodiversity in rice paddies.

In addition, it is required to establish laboratory systems for assessing the effects of farming practices, for example, agrochemical application. Given that rice paddies provide habitats for hundreds of beneficial insect species [6-8], all of these insects would be difficult to be involved in the abovementioned studies. Accordingly, it is necessary to select particular insect species or groups as indicator organisms for extensive studies $[3,9,10]$. At least, candidate species or groups should be widely distributed, commonly found, readily recognized or sampled, sensitive to agricultural practices, and easily reared in the laboratory. It is also ideal if indicator organisms reflect the level of biodiversity in agricultural land.

Insect parasitoids are among beneficial organisms, and many parasitoids have been recorded from rice paddies [11]. Most parasitoids in rice paddies are associated with lepidopteran and homopteran rice pests [12-15]. The rice skipper Parnara guttata (Bremer et Grey) is a major herbivorous rice pest in Japan $[15,16]$. Because P. guttata larvae make leaf rolls, which are visibly conspicuous, it is easy to sample this pest, and therefore parasitoids associated with P. guttata can easily be sampled.

Gregopimpla kuwanae Viereck (Hymenoptera: Ichneumonidae) has frequently been found as a gregarious ectoparasitoid of $P$. guttata $[15,17,18]$, though it is also known as an important natural enemy of the silver Y moth Autographa gamma (L.) [19]. Gregopimpla kuwanae is common and 
is widely distributed in Japan and East Asia [17] and is relatively large in size (forewing length: $5-10 \mathrm{~mm}$ ) [18]. Given its commonness in rice paddies and easiness to sample, $G$. kuwanae is a candidate indicator organism. However, it is not known whether the parasitoid can easily be reared in the laboratory. Also, its detailed biology is not known. The present study was thus undertaken to test the easiness of rearing G. kuwanae and to reveal the basic biology.

Because the natural host P. guttata is difficult to massrear, it is desirable to use laboratory hosts for the rearing system. Many previous literatures suggest that the greater wax moth Galleria mellonella (L.) is widely suitable for rearing ichneumonid parasitoids [20-22]. In addition, G. mellonella can be easily reared on artificial diets. If it is possible to rear $G$. kuwanae on this host, laboratory testing like insecticide effect evaluation will be greatly promoted.

Here, I first examined suitability of G. mellonella as a laboratory host of G. kuwanae. Second, the oviposition behavior was observed to investigate life history and reproductive characteristics of G. kuwanae. Specifically, the present study examined host acceptance, clutch size (how many eggs a female laid on each host cocoon), and offspring survival on $G$. mellonella. Third, dissection experiments were conducted to assess fecundity and reproductive mode of G. kuwanae (i.e., synovigenic or proovigenic). Such information would help understand the reproductive characteristics of G. kuwanae. Based on these results, laboratory rearing and life history of G. kuwanae are discussed.

\section{Materials and Methods}

2.1. Parasitoid and Host. A laboratory colony of G. kuwanae was established using adult parasitoids collected from rice paddies in Tsukuba, central Japan. Adults that had emerged from P. guttata collected from rice fields in Tsukuba were also used to establish the colony. Female parasitoids were placed individually in plastic containers $(10 \mathrm{~cm}$ in diameter, $4.5 \mathrm{~cm}$ in height), together with tissue paper saturated with diluted honey. The tissue paper was replaced twice a week thereafter. The containers were kept at $20 \pm 0.5^{\circ} \mathrm{C}$ under a photoperiod of $16 \mathrm{~L}: 8 \mathrm{D}$.

The colony was maintained on prepupae of a laboratory host, G. mellonella. Host cocoons containing prepupae were presented to female G. kuwanae in the plastic containers. Parasitized hosts were removed and held at $20 \pm 0.5^{\circ} \mathrm{C}$ under a photoperiod of 16L : $8 \mathrm{D}$ until parasitoid emergence. Newly emerging parasitoids were individually placed in the plastic containers. A male parasitoid was put in each container for 2-3 days to ensure all females are inseminated. Tissue paper saturated with diluted honey was placed in each container to feed the females. Female parasitoids used for experiments were F2 or F3 generations unless otherwise stated.

2.2. Host Acceptance. First, behavioral responses of $G$. kuwanae to the laboratory host G. mellonella were observed for wild-caught adult females collected in rice paddies and naïve females that emerged from the natural host $P$. guttata. Second, the oviposition behavior was observed with laboratory-reared females that emerged from G. mellonella.
The observation was made to assess whether G. mellonella was selected by G. kuwanae as an oviposition site. Cocoons containing prepupae of $G$. mellonella were presented singly to female parasitoids, and their response to the cocoons was directly observed. Each female was continuously observed for the first 15-20 min. When females did not respond to a host during this observational period, the host was kept left in the container for 3-5 hours with the same females and was examined about every hour to confirm whether it was attacked or not. Host cocoons were dissected to confirm whether parasitoid eggs were present on host body surface. In all, 6 wild-caught females of unknown age, 12 females that emerged from wild-caught $P$. guttata, and 10 laboratoryreared females that emerged from G. mellonella were used. Except for wild-caught females, mated female parasitoids aged 0-4 days were used. The observations were made at room temperature around $26^{\circ} \mathrm{C}$.

2.3. Oviposition. The oviposition behavior of G. kuwanae on the laboratory host G. mellonella was observed. As a preexperimental treatment, individual females for testing were provided with two host cocoons after emergence. The two host cocoons were left in contact with the female parasitoid for one day and were replaced with fresh cocoons every day. All host cocoons were dissected to examine whether the females oviposited on them. These treatments ensured all test females respond to the laboratory host, thus enabling the following observation.

Oviposition behavior and clutch size were examined using mated females of 5-6 days old that had at least oviposited on one host. Host cocoons were singly offered to individual females in the container. When females mounted hosts, their responses to the hosts were directly observed (i.e., host rejection, ovipositor insertion, oviposition, and host feeding). Hosts were removed from the container immediately after the females had left the hosts. By doing so, multiple attacks on each host were avoided. Time taken for oviposition was measured. Host cocoons that had been parasitized or fed upon were carefully dissected. With the aid of fine scissors, cocoons were longitudinally cut and opened, and the number of eggs laid was counted. Host cocoons dissected were then wrapped carefully with tissue paper and used in the following experiment. This treatment itself did not affect the successful pupation of unparasitized hosts. Also, preliminary observations suggested offspring parasitoid survival was not affected if host cocoons once opened were wrapped as mentioned above. In all, 12 females were used in the experiment. Other experimental procedures were the same as those mentioned above.

2.4. Parasitoid Offspring Survival. Hosts used in the above experiment were used for investigation of offspring survival rate. Hosts parasitized by females that had been deprived of host for three days were added to examine the effect of large clutch size on offspring survival. Parasitized hosts enrolled with tissue paper were individually placed in plastic containers $(6.5 \mathrm{~cm}$ in diameter, $3.5 \mathrm{~cm}$ in height). Parasitized hosts were then kept at $20 \pm 0.5^{\circ} \mathrm{C}$ under a photoperiod of 16L : 8D until parasitoid emergence. After one month since 
parasitism, hosts were dissected to examine the number and the stages of dead parasitoids within the host cocoon. Because G. kuwanae was relatively large and ectoparasitic, it was possible to examine dead parasitoids and the stages by the naked eye. The larval stage was classified into early and late instars. When the size of dead larvae was almost identical to that of eggs, the larvae were regarded as early instars. Larvae that were clearly larger than eggs were classified as late instars. Thus, exact distinction of larval instars was not made because it is not known how many larval instars are there until maturation of G. kuwanae. Percent survival was calculated on the basis of the number of eggs laid and that of parasitoids that successfully emerged from the host.

2.5. Egg Load. This experiment was carried out to assess the egg load of female G. kuwanae. The numbers of mature and immature eggs that females carried at any one time are used as the index. Mated female parasitoids aged 10-12 days were dissected under a binocular stereoscope to observe the morphology of the ovary, and the numbers of mature and immature eggs were counted. 10-12-day-old females were used because female $G$. kuwanae has a relatively long lifetime of ca. one month at $20^{\circ} \mathrm{C}$ and because, within these ages, all females extensively repeated host-feeding/oviposition cycles. After dissection, forewing length (right wing) of females was measured under a binocular stereoscope (minimum unit: $0.01 \mathrm{~mm}$ ). Test females were provided with tissue paper saturated with diluted honey and were allowed access to hosts every two days for 8-10 days after adult female emergence. In total, 35 females were used in this experiment. Nine newly emerging females were also dissected to examine whether female G. kuwanae emerged with or without eggs. Eggs that were well formed with a smooth surface were categorized as mature eggs and those with a rough surface, or attached by nurse cells, as immature eggs.

2.6. Voucher Specimens. Specimens of G. kuwanae used in the present study are deposited at the Institute of Biological Control, Kyushu University.

2.7. Statistical Analyses. Statistical treatments were made with the aid of JMP version 10.0 (SAS Institute).

\section{Results}

3.1. Host Acceptance. Among six wild-caught adult Gregopimpla kuwanae, two females attacked G. mellonella cocoons within 1-2 hours. However, the remaining four wild-caught females took 1-2 days to begin attacking $G$. mellonella cocoons. Once wild-caught females had accepted G. mellonella cocoons for oviposition, they readily attacked G. mellonella cocoons thereafter, suggesting involvement of learning effects. For G. kuwanae, which had emerged from P. guttata collected in the field, females of 1 day old did not respond to nor attack $G$. mellonella cocoons $(N=12)$. When $G$. mellonella cocoons had been kept placed in rearing plastic containers, the cocoons were mostly attacked within 3-4 days since female emergence.
Direct behavioral observations showed that young females of 1-3 days old with no previous experience on $G$. mellonella cocoons often did not respond to the cocoons even when they passed by the cocoons $(N=22)$. Once female $G$. kuwanae had attacked a host cocoon, it readily responded to host cocoons and attacked them thereafter. The first 1-3 hosts that had been attacked were not used for oviposition. Young females of G. kuwanae used them only for feeding purposes.

3.2. Oviposition. In all, 95 hosts were given to gravid females. Among them, $92.6 \%$ of hosts were attacked by female $G$. kuwanae. Seven hosts were rejected for oviposition after antennation, that is, external host rejection (7.4\%). This low value for external host rejection suggested that $G$. mellonella was highly acceptable for G. kuwanae. Hosts rejected for attack, that is, ovipositor probing, were generally small, suggesting that host size was important for host acceptance in G. kuwanae. Seventy hosts (73.7\%) were parasitized.

Eighteen hosts were used exclusively for host-feeding purposes after attack with the ovipositor (\% host feeding = $18.9 \%)$. Gregopimpla kuwanae was typically a destructive host feeder. Hosts used for feeding were heavily damaged mainly by the mandibles of the female. In fact, 18 hosts that had been fed upon by the female parasitoid did not pupate and died. No internal host rejection, that is, host rejection based on internal examination of hosts with the ovipositor, was observed, and hosts that had once been accepted for ovipositor probing were used either for oviposition or for host feeding.

Female G. kuwanae spent relatively much time for oviposition. Mean handling time required to oviposit on $G$. mellonella cocoons was $14.2 \pm 11.8 \mathrm{~min}( \pm \mathrm{SD})$. After the first ovipositor insertion, during which the female probably injected venom with the ovipositor, the female pulled out the ovipositor from the host and stood still on a host cocoon until the venom became effective, and this behavior resulted in relatively long oviposition time. After the stung host had been paralyzed, the female inserted the ovipositor into the host again and laid eggs on the defenseless host.

To examine clutch size, 42 parasitized hosts were dissected. Eggs were laid on the surface of host body within the cocoon. The mean number of eggs laid on each host was $3.50 \pm 2.41( \pm \mathrm{SD})$ with a range from 1 up to 13 (Figure 1(a)). Superparasitism or multiple attacks were not involved because each female had been allowed to attack hosts once in the experiment.

Careful observations demonstrated that parasitoid eggs on each host were not uniformly placed on host body but consisted of 1-4 subclutches of eggs (Figure 1(b)). The mean number of such subclutches with SD was $1.69 \pm 0.75$. The number of subclutches increased with total numbers of eggs laid (clutch size) (regression analysis; $r^{2}=0.34, t=3.60$, $P=0.0014$ ). This indicated that female G. kuwanae did not place all eggs in one location on the host body but divided eggs into a few subclutches.

3.3. Parasitoid Offspring Survival. The eggs of the parasitoid on host are white in color and did not increase the volume during development, indicating that they are typically of anhydropic egg type. Gregopimpla kuwanae larvae fed on 


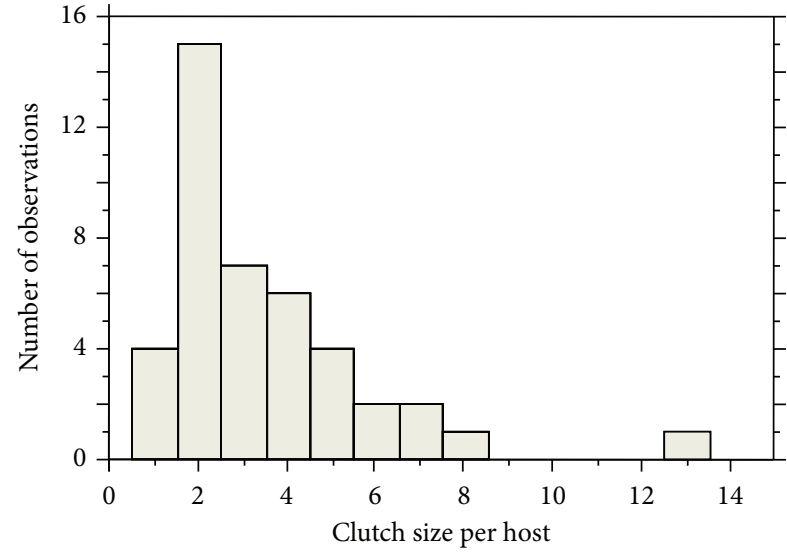

(a)

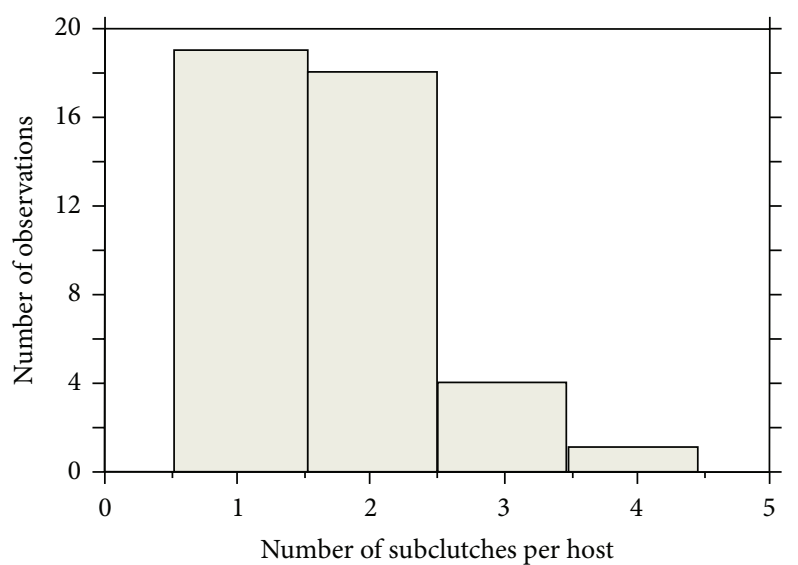

(b)

FIGURE 1: Frequency distribution of the number of eggs laid on each G. mellonella cocoon (clutch size) by G. kuwanae (a) and the number of subclutches of eggs placed on each host (b).

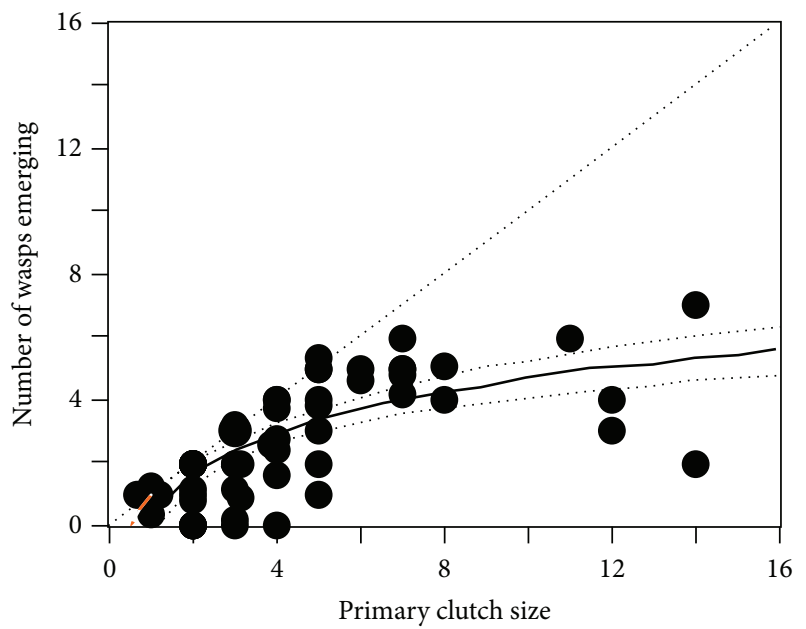

(a)

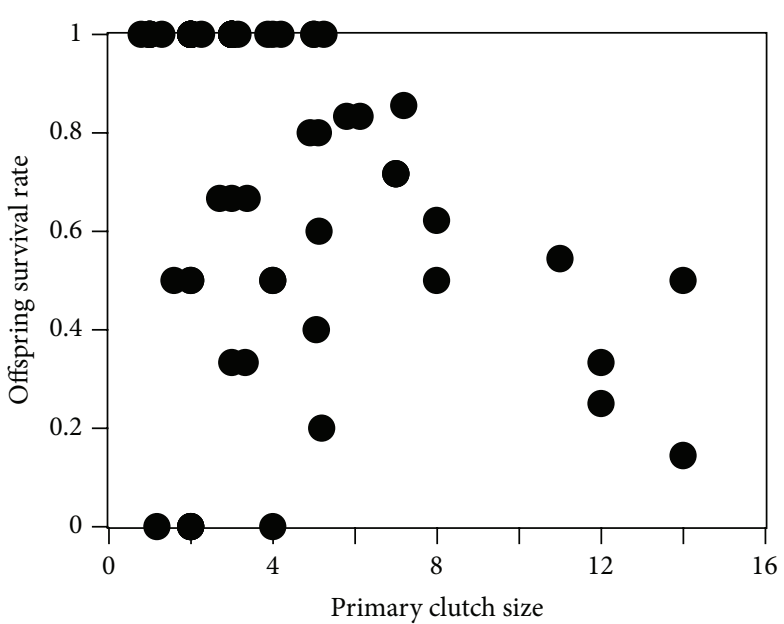

(b)

FIGURE 2: Relationships between clutch size and number of parasitoid offspring emerging (a) or offspring survival (b). Dotted lines indicated $95 \%$ confidence intervals. A positive relationship was detected for the former (regression analysis; $P<0.001$ ) whereas a negative relationship was detected for the latter (Kendall rank correlation test; $P<0.001$ ).

the host from external positions and thus developed as an ectoparasitoid. Each host produced up to seven parasitoid offspring. The percentage of hosts that produced parasitoid offspring was $91.4 \%(N=70)$. These results indicated that G. mellonella was suitable for offspring development. No significant relationship was found between clutch size and probability of hosts producing at least one parasitoid offspring (logistic regression analysis; $\chi^{2}=2.13, P=0.25$ ).

The gregarious ectoparasitoid G. kuwanae laid multiple eggs on each host. Each host received variable numbers of parasitoid eggs and consequently produced different numbers of parasitoid offspring. Therefore, the relationship between numbers of eggs laid per host (i.e., clutch size) and those of parasitoid offspring successfully emerging from each host was examined. The number of parasitoid offspring increased with clutch size (Figure 2(a); regression analysis after $\log$ transformation of independent variables; $r^{2}=0.50$, $t=8.27, P<0.0001)$. However, rate of the increment decreased with increasing clutch sizes (Figure 2(a)), suggesting that the survival of parasitoid eggs to adulthood differed depending on clutch size.

Then, the relationship between clutch size and offspring survival on each host (measured as numbers of adult parasitoids emerging) was examined. Kendall's rank correlation test showed a negative relationship between the two (Figure 2(b); $N=70$, Kendall's tau $=0.26, P=0.007$ ); the survival of offspring parasitoids decreased with increasing clutch size. The mean offspring survival on each host was $70.1 \%$ (Figure 3). Offspring mortality took place mainly during the earliest stage of development and before parasitoid emergence (Figure 3; chi-squared test, $\chi^{2}=20.1, \mathrm{df}=5, P=0.0005$ ). Parasitoid offspring size decreased with the increasing number of eggs on each host. These results suggested the presence of a scramble type of larval competition for host resources. 


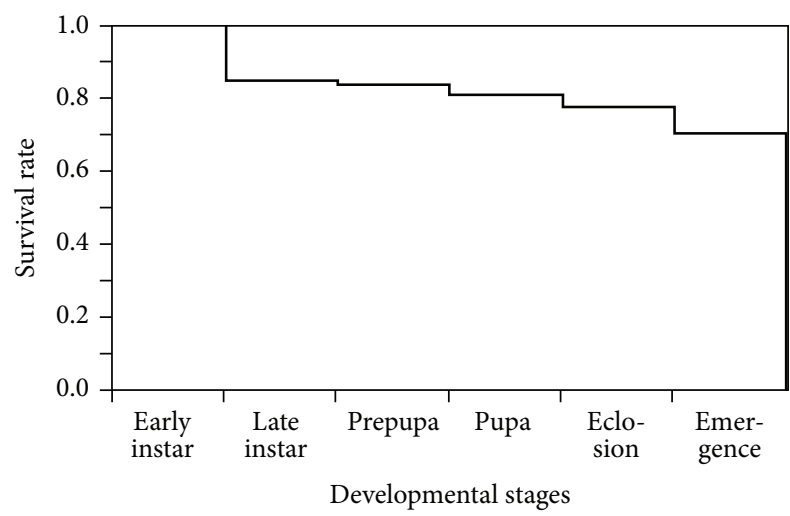

Figure 3: Survival curve of G. kuwanae on G. mellonella.

3.4. Egg Load. Dissection experiments revealed that egg load differed among females of different sizes. Larger female wasps carried greater numbers of mature and immature eggs (regression analyses; $N=35, r^{2}=0.13, F=4.79, P=0.03$ for mature eggs; $N=35, r^{2}=0.42, F=24.2, P<0.0001$ for immature eggs) (Figure 4). In addition, larger females had greater numbers of ovarioles (regression analyses; $N=$ $35, r^{2}=0.59, F=35.5, P<0.0001$ ) (Figure 5(a)). A simple regression analysis also showed that no significant relationship existed between mature egg load and ovariole number $\left(N=35, r^{2}=0.08, F=1.95, P=0.18\right)$ (Figure 5(b)). Thus, the fecundity of females was influenced through the number of eggs per ovariole. Dissection experiments with newly emerging females have revealed that female G. kuwanae carried few fat bodies at emergence. Also, they had no mature and immature eggs in the ovary. Gregopimpla kuwanae therefore produced eggs after wasp emergence.

\section{Discussion}

4.1. Suitability of G. mellonella for Rearing G. kuwanae. Host acceptance experiments have demonstrated that G. mellonella cocoons are acceptable for female G. kuwanae although $G$. mellonella is not a natural host for G. kuwanae. However, at least young females of 1-4 days old do not respond to host cocoons presented. This may be because G. mellonella is not a natural host or may simply be because they are not at maturity. Alternatively, the host species may be perceived as a low quality host by the female. In any case, the observations have revealed that G. mellonella cocoons should be kept placed in rearing containers to allow the young female to recognize and attack the cocoons. Galleria mellonella cocoons may share some of the host cues that are used by G. kuwanae to recognize the host. A likely cue that is in common could be the morphology of "cocoon." Parasitoids use a combination of different cues to recognize their host, and host physical features are among the cues [23-25]. The morphology of "cocoon" itself may cause G. kuwanae to attack G. mellonella cocoons.

G. mellonella can be used as a laboratory host. Offspring survival of G. kuwanae on G. mellonella was high, and ca. $90 \%$ of parasitized hosts produced parasitoid offspring. This result indicates that G. mellonella is suitable for offspring development of G. kuwanae. G. mellonella has often been shown as a suitable laboratory host for many ichneumonid parasitoids attacking lepidopterans [20-22], and this holds true for G. kuwanae. This host is an ideal laboratory host because it is easy to mass-rear in the laboratory.

4.2. Clutch Size and Offspring Survival. Female G. kuwanae laid on average 3.5 eggs on G. mellonella. This value appears to be lower than mean clutch size on a natural host, Clostera anastomosis. Gregopimpla kuwanae in the field lays around 10 eggs per host when it attacks $C$. anastomosis [18]. Likewise, when P. guttata is a host, G. kuwanae lays 6-10 eggs per host (T. Ueno, personal observations). Natural hosts recorded for G. kuwanae are larger than G. mellonella [17, 19]. Low clutch size on G. mellonella may result from the fact that this laboratory host is smaller than natural hosts.

Clutch size was variable among parasitized hosts in $G$. kuwanae (Figure 1). The offspring survival decreased with increasing clutch sizes (Figure 2). A number of studies with gregarious parasitoids have shown that larger clutch size imposes greater larval mortality [26, 27]. Given that host resources are limited in amount, large clutches should result in competition for the resources among the developing parasitoids. Thus, it is a logical consequence that offspring survival in G. kuwanae decreases with increasing clutch sizes.

Although clutch size is highly variable in G. kuwanae, 70\% of parasitized hosts receive clutches of eggs between 2 and 5 when hosts have been provided every day. Mean offspring survival on each host (with SD) was $70.5 \pm 38.2 \%$ when clutch size was between 2 and 5 . This mean value of survival appears to be sufficiently high for rearing G. kuwanae. Thus, G. mellonella would be a suitable host though the number of parasitoid eggs laid on this host is smaller than that on natural hosts.

4.3. Reproduction and Potential Fecundity. The present observations have demonstrated that, like other members of the tribe Ephialtini in the subfamily Pimplinae, G. kuwanae requires host body fluids to produce eggs and that host feeding precedes oviposition [28]. Many synovigenic parasitoids produce yolk-rich eggs, that is, anhydropic eggs, and, in such parasitoids, adult nutrition is important because females invest substantial resources to egg production [29-31]. The ectoparasitoid G. kuwanae laid relatively large, yolk-rich eggs that are of the anhydropic type [28]. They may thus acquire resources for egg production by feeding upon hosts. Like many synovigenic parasitoids, host feeding will be important for female reproduction in G. kuwanae.

Female G. kuwanae was found to emerge with no mature eggs. In members of Pimplinae (such as Pimpla spp. and Itoplectis spp.), females emerge with no eggs but they emerge with fat bodies as nutritional reserves, which are used for egg production after emergence [32, 33]. In contrast, the present observation has revealed that newly emerging females of G. kuwanae have few fat bodies, regardless of whether they emerge from natural or laboratory hosts, suggesting that they have few nutritional reserves at adult emergence. This finding can explain why host feeding precedes oviposition in this 


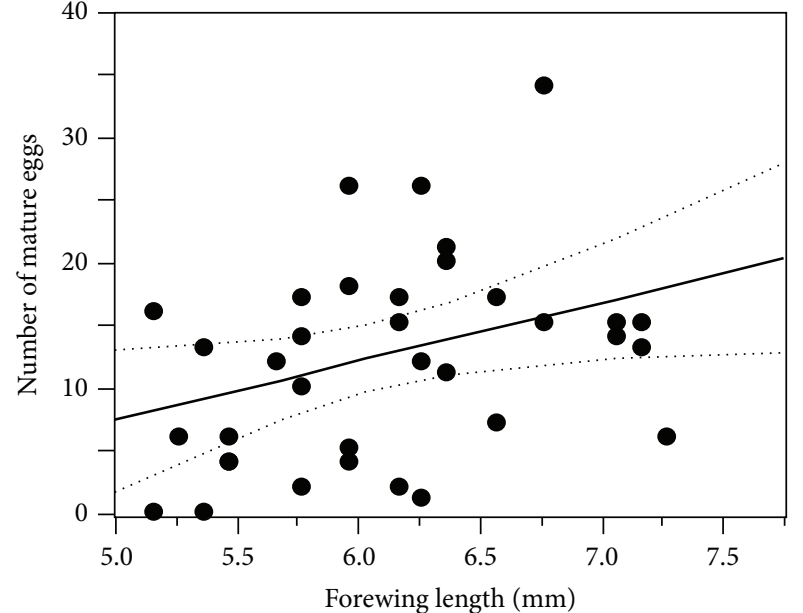

(a)

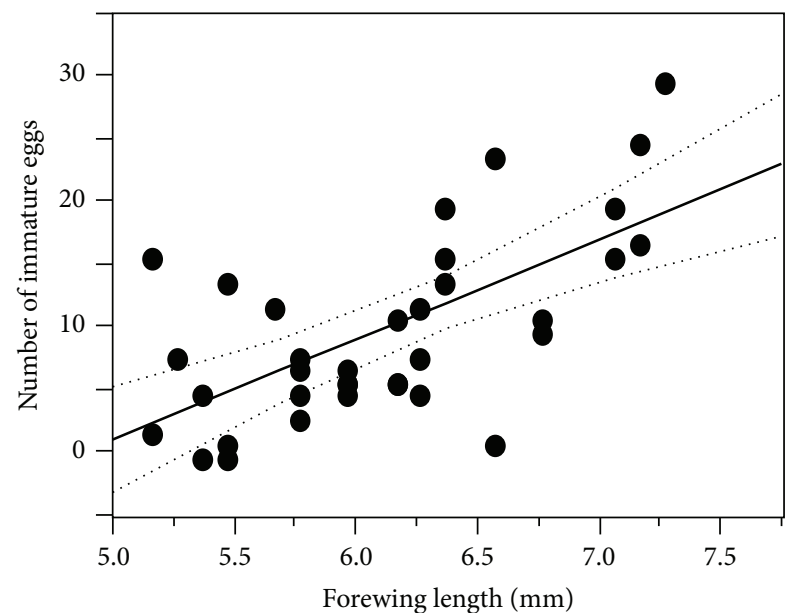

(b)

Figure 4: Relationships between female size and egg load. Dotted lines indicated 95\% confidence intervals. For both mature and immature egg loads, significantly positive relationships were detected (regression analyses; $P<0.001$ ).

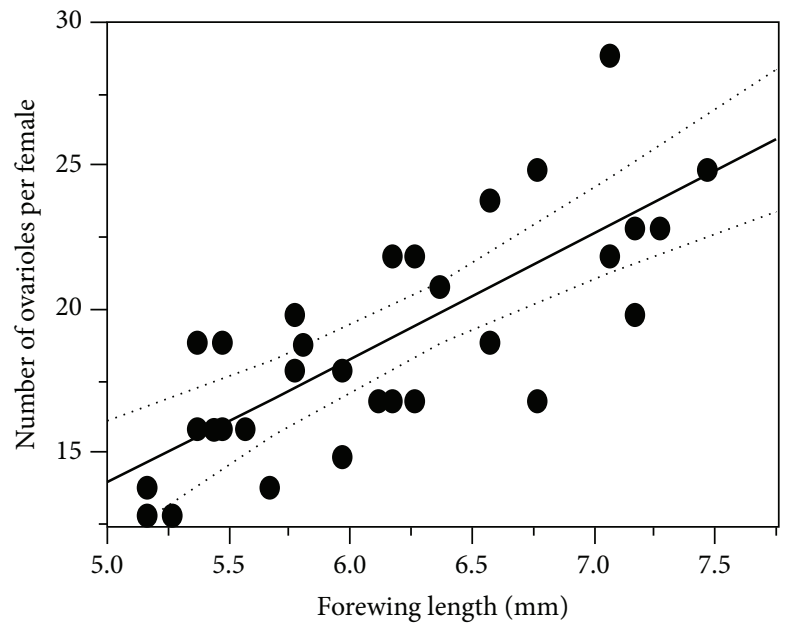

(a)

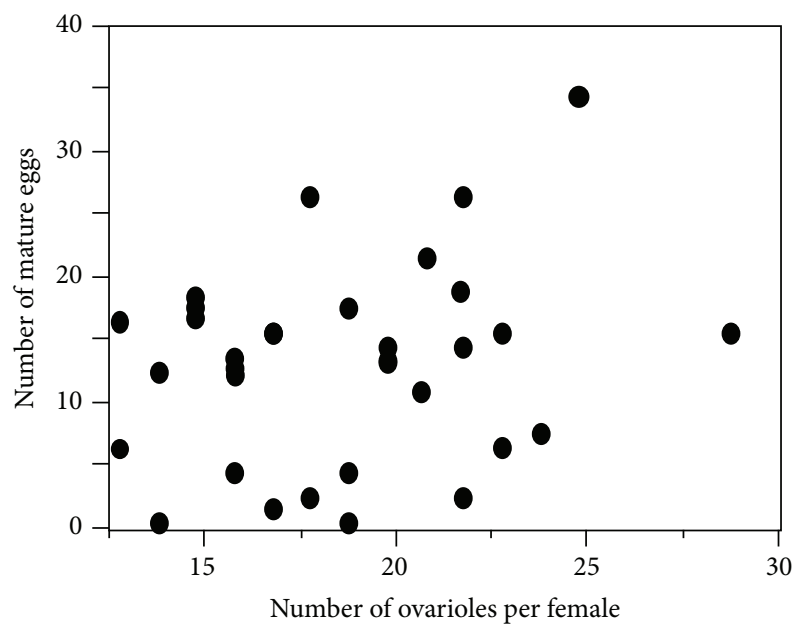

(b)

FIGURE 5: Relationships between female size and ovariole number (a) and between ovariole number and mature egg load (b). Dotted lines indicated $95 \%$ confidence intervals. A significantly positive relationship was detected for the former (regression analyses; $P<0.0001$ ) whereas ovariole numbers did not relate to the number of mature eggs (regression analyses; $P=0.18$ ).

parasitoid; they have to feed on hosts first to start oogenesis. Thus, G. kuwanae is classified as a parasitoid with the ovigeny index 0 , that is, extremely synovigenic species [30,31].

Fecundity of female parasitoids greatly varies from species to species [34-36]. Dissection of female reproductive organs, that is, ovary, can reveal the reproductive potential of female parasitoids across the species level [36]. The number of ovarioles that a female has can reflect egg production rate and hence correlate with fecundity; parasitoid species having a greater number of ovarioles often have a greater egg load. The morphology of lateral oviducts also suggests egg storage capacity of female parasitoids $[34,35]$. Parasitoid species that have wider oviducts store a greater number of mature eggs.

Thus, dissection experiments to examine the ovary morphology are a convenient method to evaluate parasitoid reproductive potential, that is, egg production and fecundity. Body size of female parasitoids is a relatively reliable proxy of fecundity that is practically easy to measure although any single laboratory measure regarding reproduction may not properly reflect realized reproductive success in the field [37]. Positive relationships between female size and fecundity within the species level are common for many parasitoid wasps including gregarious species [27, 38-40]. Ovariole number is variable even within the species level and may correlate with female size $[21,34]$. Thus, examination of the morphology of the ovary can also give an insight into the mechanism of fecundity variation within a species.

The current study has shown that the number of ovarioles is highly variable among females of G. kuwanae and that larger G. kuwanae have a greater number of ovarioles 
(Figure 5). Dissection experiments have also shown a positive relationship between female size and egg load in G. kuwanae (Figure 4). This suggested that larger female wasps had a greater reproductive potential. Greater fecundity in larger female parasitoids may be attributed to their size itself or to the greater number of ovarioles. The present study has shown that ovariole numbers are not a determinant for female fecundity in G. kuwanae (Figure 5). How female size affects fecundity is not known in G. kuwanae. A possible explanation could be that larger females are able to store more nutritional reserves from single host meal, producing more eggs at any one time.

4.4. Potential as an Indicator. As mentioned in the Introduction, the parasitoid wasp G. kuwanae fulfills at least some of the prerequisites as a bioindicator. In addition, the present study has revealed that G. kuwanae can easily be reared on the laboratory host, G. mellonella, and, with this host, mass-rearing will be possible. Because G. kuwanae is a large parasitoid, handling of this parasitoid would be easy, making it a potentially good experimental parasitoid to assess the lethal and sublethal impacts of pesticides. However, there are a number of aspects to be examined. It is not known whether the parasitoid is sensitive to agricultural practices such as agrochemical use. Preliminary experiments suggest that G. kuwanae is very sensitive to synthetic pesticides (Ueno, unpublished). Also, whether the presence and density of G. kuwanae can reflect biodiversity in rice paddies is unclear although the biodiversity of ichneumonid parasitoids including G. kuwanae is lower in rice paddies with more pesticide inputs $[8,9]$. Because there are still a number of candidate parasitoids in rice paddies, comparing studies involving candidate parasitoids would be necessary to select indicator parasitoids for environmental evaluation in the paddy field of Japan. A series of studies are currently being undertaken to explore suitable indicators.

\section{Conflict of Interests}

The author declares that there is no conflict of interests regarding the publication of this paper.

\section{Acknowledgments}

This work was partly supported by grants from the Ministry of Agriculture, Forestry and Fisheries of Japan (Research Project: Development of Technologies for Mitigation and Adaptation to Climate Change in Agriculture, Forestry and Fisheries) and from the Ministry of Education, Sciences, Sports and Culture of Japan (no. 13760039).

\section{References}

[1] M. Kogan and J. D. Lattin, "Insect conservation and pest management," Biodiversity and Conservation, vol. 2, no. 3, pp. 242-257, 1993.

[2] W. Büchs, "Biotic indicators for biodiversity and sustainable agriculture-introduction and background," Agriculture, Ecosystems and Environment, vol. 98, no. 1-3, pp. 1-16, 2003.
[3] W. Büchs, "Biodiversity and agri-environmental indicatorsgeneral scopes and skills with special reference to the habitat level," Agriculture, Ecosystems and Environment, vol. 98, no. 1-3, pp. 35-78, 2003.

[4] G. Benckiser and S. Schnell, Biodiversity in Agricultural Production Systems, CRC Press, Boca Raton, Fla, USA, 2006.

[5] D. I. Jarvis, C. Padoch, and H. D. Cooper, Managing Biodiversity in Agricultural Ecosystems, Columbia University Press, New York, NY, USA, 2007.

[6] K. Yano, Insect Fauna in Paddy Field, Tokai University Press, Tokyo, Japan, 2002.

[7] K. Kiritani, A Comprehensive List of Organisms Associated with Paddy Ecosystems in Japan, Daido Shikou Printing, Saga, Japan, 2009.

[8] T. Ueno, "Insect natural enemies as bioindicators in rice paddies," CNU Journal of Agricultural Science, vol. 39, no. 4, pp. 545-553, 2012.

[9] T. Ueno, "Bioindicators of biodiversity and farming practice in rice paddies," International Journal of Chemical, Environmental \& Biological Sciences, vol. 1, no. 1, pp. 84-87, 2013.

[10] N. Dudley, D. Baldock, R. Nasi, and S. Stolton, "Measuring biodiversity and sustainable management in forests and agricultural landscapes," Philosophical Transactions of the Royal Society B: Biological Sciences, vol. 360, no. 1454, pp. 457-470, 2005.

[11] K. Yasumatsu and C. Watanabe, A Tentative Catalogue of Insect Natural Enemies of Injurious Insects in Japan. Part 2. Host Parasite-Predator Catalogue, Entomological Laboratory, Kyushu University Press, Fukuoka, Japan, 1965.

[12] S. Momoi, "Ichneumonidae (Hymenoptera) collected in paddy fields of the Orient with descriptions of new species," Mushi, vol. 40, pp. 1-11, 1966.

[13] T. Nishida and T. Torii, Rice Stem-Bores and Their Natural Enemies, IBP Handbook no. 14, The International Biological Program, Blackwell Scientific Publications, Oxford, UK, 1970.

[14] M. Kobayashi and T. Wada, "Hymenopterous parasites of the rice leaf roller, Cnaphalocrocis medinalis GUENEE, and their activities observed in the paddy fields of Chikugo," Kyushu Plant Protection Research, vol. 25, pp. 64-66, 1979.

[15] M. Matsumura, "Life tables of the migrant skipper, Parnara guttata guttata Bremer et Grey (Lepidoptera: Hesperiidae) in the northern peripheral area of its distribution," Applied Entomology \& Zoology, vol. 27, no. 3, pp. 331-340, 1992.

[16] F. Nakasuji, "Population dynamics of a migrant skipper butterfly Parnara guttata (Lepidoptera: Hesperiidae) II. Survival rates of immature stages in paddy fields," Researches on Population Ecology, vol. 24, no. 1, pp. 157-173, 1982.

[17] H. Townes, S. Momoi, and M. Townes, A Catalogue and Reclassification of the Eastern Palearctic Ichneumonidae, vol. 5 of Memoris of the American Entomological Institute, 1965.

[18] S. Momoi and E. Nisida, "The effect of crowding in Gregopimpla kuwanae (Hymenoptera: Ichneumonidae): a comparison with its sympatric sibling species," Odokon-Chugoku, vol. 36, pp. 2935, 1994.

[19] J. Kaneko and K. Konishi, "Rate of Parasitism of Cocoons of Silver Y Moth, Autographa gamma (L.) in Grass Fields at Sapporo, Japan and species composition of parasitoids," Japanese Journal of Applied Entomology \& Zoology, vol. 39, no. 2, pp. 162-164, 1995.

[20] A. Syed, "New rearing device for Exeristes roborator (F.) (Hymenoptera: Ichneumonidae)," Journal of Economic Entomology, vol. 78, no. 1, pp. 279-281, 1985. 
[21] T. Ueno and T. Tanaka, "Comparative biology of six polyphagous solitary pupal endoparasitoids (Hymenoptera: Ichneumonidae): differential host suitability and sex allocation," Annals of the Entomological Society of America, vol. 87, no. 5, pp. 592-598, 1994.

[22] T. Ueno, "Biology of the ectoparasitoid wasp Agrothereutes lanceolatus (Hymenoptera: Ichneumonidae): host acceptance and larval development on a laboratory host," Journal of the Faculty of Agriculture, Kyushu University, vol. 47, no. 1, pp. 3743, 2002.

[23] A. P. Arthur, "Host acceptance by parasitoids," in Semiochemicals: Their Role in Pest Control, D. A. Nordlund, R. L. Jones, and W. J. Lewis, Eds., pp. 97-120, John Wiley \& Sons, New York, NY, USA, 1981.

[24] S. B. Vinson, "Host selection by insect parasitoids," Annual Review of Entomology, vol. 21, no. 1, pp. 109-133, 1976.

[25] D. L. J. Quicke, Parasitic Wasps, Chapman \& Hall, London, UK, 1997.

[26] J. K. Waage and H. C. J. Godfray, "Reproductive strategies and population ecology of insect parasitoids," in Behavioural Ecology: Ecological Consequences of Adaptive Behaviour, R. M. Sibley and R. H. Smith, Eds., pp. 449-470, Blackwell, Oxford, UK, 1985.

[27] H. C. J. Godfray, Parasitoids: Behavioral and Evolutionary Ecology, Princeton University Press, Princeton, NJ, USA, 1994.

[28] M. A. Jervis and N. A. Kidd, "Host-feeding strategies in hymenopteran parasitoids," Biological Reviews, vol. 61, no. 4, pp. 395-434, 1986.

[29] M. A. Jervis, N. A. C. Kidd, and G. E. Heimpel, "Parasitoid adult feeding behaviour and biocontrol-a review," Biocontrol News and Information, vol. 17, pp. 11-26, 1996.

[30] M. A. Jervis, G. E. Heimpel, P. N. Ferns, J. A. Harvey, and N. A. C. Kidd, "Life-history strategies in parasitoid wasps: a comparative analysis of 'ovigeny,' Journal of Animal Ecology, vol. 70, no. 3, pp. 442-458, 2001.

[31] M. A. Jervis, J. Ellers, and J. A. Harvey, "Resource acquisition, allocation, and utilization in parasitoid reproductive strategies," Annual Review of Entomology, vol. 53, pp. 361-385, 2008.

[32] T. Ueno, "Reproduction and host-feeding in the solitary parasitoid wasp Pimpla nipponica (Hymenoptera: Ichneumonidae)," Invertebrate Reproduction and Development, vol. 35, no. 3, pp. 231-237, 1999.

[33] T. Ueno and K. Ueno, "The effects of host-feeding on synovigenic egg development in an endoparasitic wasp, Itoplectis naranyae," Journal of Insect Science, vol. 7, article 46, 2007.

[34] K. Iwata, "The comparative anatomy of the ovary in Hymenoptera. Part V. Ichneumonidae," Acta Hymenopterologica, vol. 1, pp. 115-169, 1960.

[35] P. W. Price, "Reproductive strategies in parasitoid wasps," The American Naturalist, vol. 107, no. 957, pp. 684-693, 1973.

[36] P. W. Price, "Strategies for egg production," Evolution, vol. 28, no. 1, pp. 76-84, 1974.

[37] B. D. Roitberg, G. Boivin, and L. E. M. Vet, "Fitness, parasitoids, and biological control: an opinion," The Canadian Entomologist, vol. 133, no. 3, pp. 429-438, 2001.

[38] K. E. Flanagan, S. A. West, and H. C. J. Godfray, "Local mate competition, variable fecundity and information use in a parasitoid," Animal Behaviour, vol. 56, no. 1, pp. 191-198, 1998.

[39] T. Ueno, "Adult size and reproduction in the ectoparasitoid Agrothereutes lanceolatus Walker (Hym., Ichneumonidae)," Journal of Applied Entomology, vol. 123, no. 6, pp. 357-361, 1999.
[40] T. Ueno, "Host-size-dependent sex ratio in a parasitoid wasp," Researches on Population Ecology, vol. 41, no. 1, pp. 47-57, 1999. 

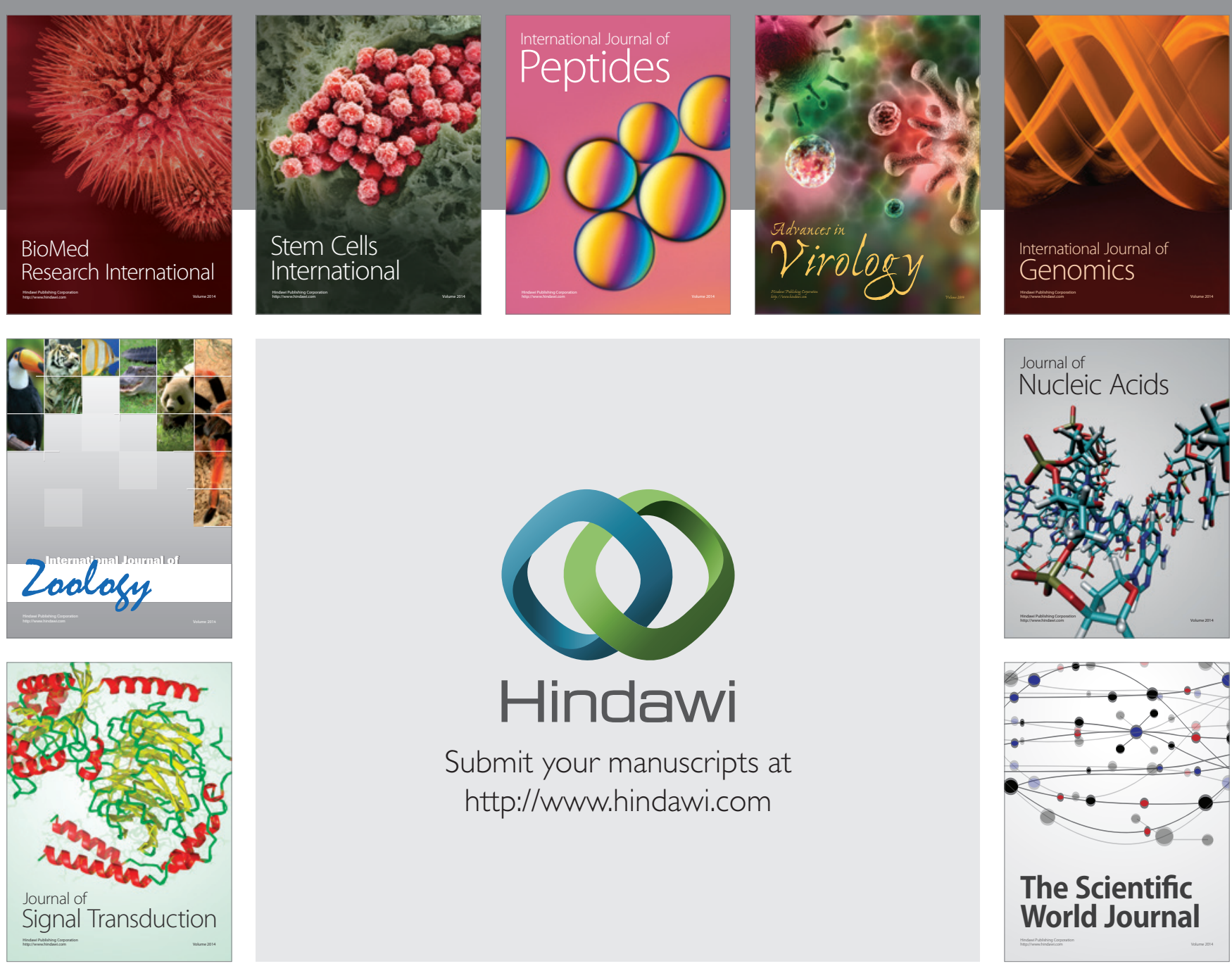

Submit your manuscripts at

http://www.hindawi.com
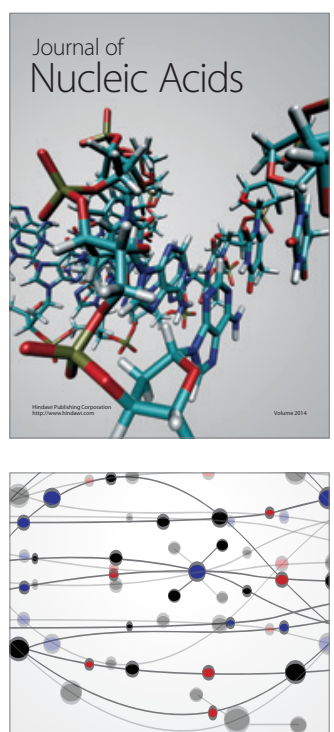

The Scientific World Journal
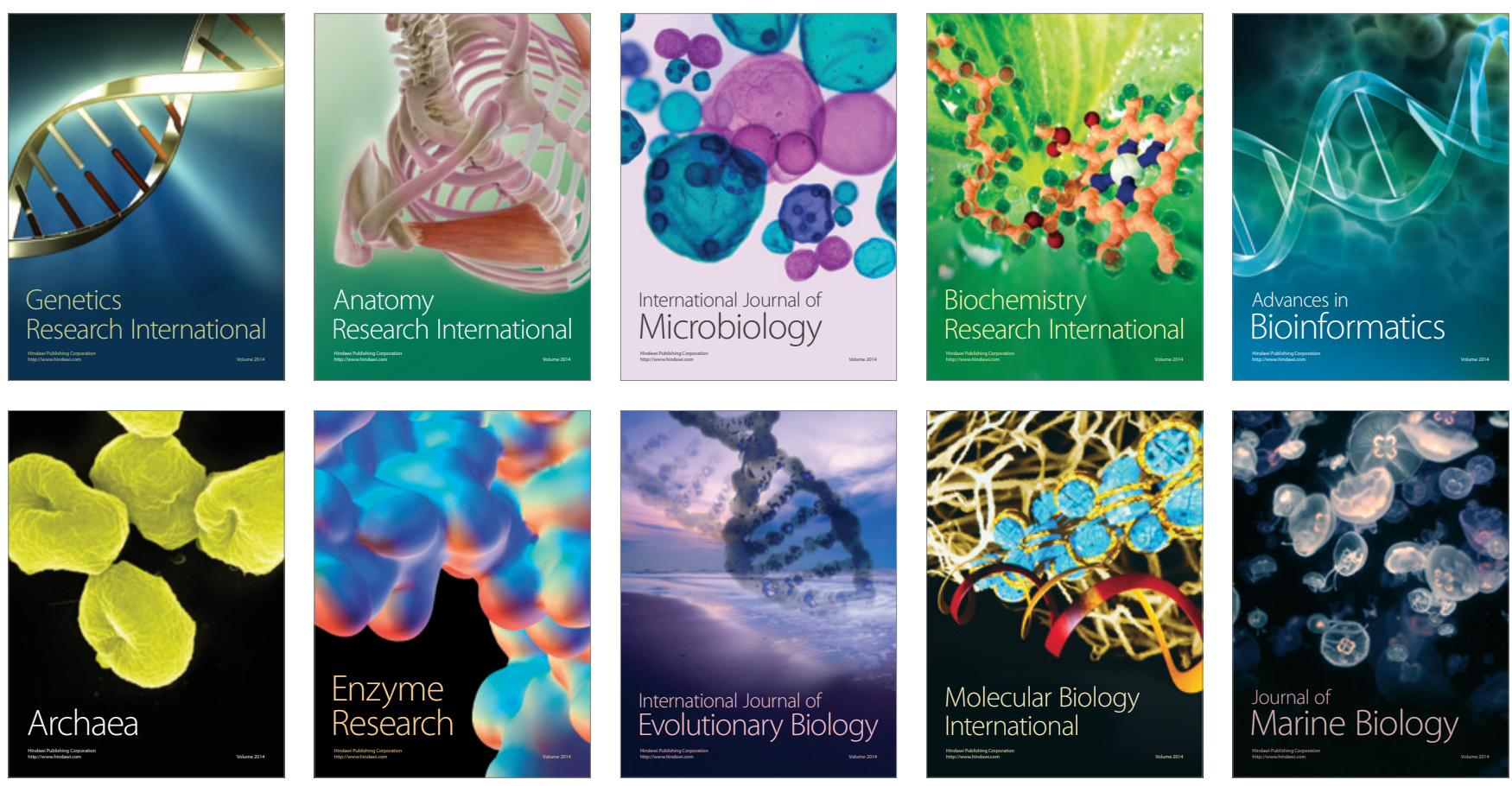